\title{
Memória visuoespacial e cinestésica de curto prazo em crianças de 7 a 10 anos
}

\author{
Cesar Galera \\ Adriana Lis Pereira de Souza \\ Universidade de São Paulo - Ribeirão Preto
}

\begin{abstract}
Resumo
Nós investigamos a memória visuoespacial e cinestésica de curto prazo em crianças entre 7 e 10 anos utilizando a tarefa de Blocos de Corsi. O desempenho melhora com a idade, é afetado pela extensão das séries e pelo número de cruzamentos. O desempenho é melhor na modalidade visual do que na cinestésica; ambas as modalidades são afetadas da mesma forma pela extensão e pelo número de cruzamentos. As curvas de posição serial apresentam forte efeito de primazia; o efeito de recência está presente apenas na modalidade visual. Nas séries com seis e sete blocos, quando considerado o número de cruzamentos, o desempenho tende a melhorar numa taxa mais elevada para a modalidade visual do que para cinestésica. Os resultados não permitem supor um sistema de memória cinestésico independente do espacial, mas sugere que ambos contribuem para o desempenho na tarefa de Corsi.
\end{abstract}

Palavras-chave: Memória visuoespacial; memória cinestésica; teste de blocos de Corsi.

\begin{abstract}
Visuospatial and kinesthetic short-term memory in children between 7 and 10 years old. We investigated the visuo-spatial and kinesthetic short term memory in children aged between 7 and 10 years through the Corsi Block test. The results showed that performance gets better with age that it is affected by sequence extension and by number of crossings paths. The performance is better in the visual modality than in the kinesthetic one; both modalities are affected in the same way by the sequence extension and number of crossing paths. Serial position curves are marked by primacy effect; recency effect is present just in visual modality. In sequences with six and seven blocks, when considered the number of crossing paths, the performance tends to get better in a higher tax for visual modality than for kinesthetic. The results do not support a kinesthetic memory independent of the spatial system, but suggests that both components contribute to the performance in the Corsi block test.
\end{abstract}

Keywords: visuospatial memory; kinesthetic memory; Corsi block test.

A memória de trabalho tem a função de armazenar a informação recebida do ambiente, transformá-la e relacioná-la às informações relevantes armazenadas na memória de longo prazo. No modelo proposto por Baddeley $(2000,2007)$ a memória de trabalho envolve quatro subsistemas funcionais distintos, sendo três armazenadores e um processador central. O laço fonológico, que armazena a informação verbal e auditiva, é composto por um armazenador passivo e por um sistema de recitação articulatória, que fortalece os traços de memória. A informação referente aos objetos e às relações espaciais entre eles, seja informação presente no ambiente ou gerada pela imaginação visual, é armazenada pelo esboço visuoespacial. O buffer episódico teria a função de integrar e armazenar temporariamente, em representações complexas, as informações armazenadas nos outros subsistemas, assim como aquela recuperada da memória de longo prazo. $\mathrm{O}$ executivo central teria a função de controle e coordenação dos subsistemas de armazenamento em uma vasta gama de tarefas, principalmente naquelas que apresentam alguma novidade para o sujeito (Baddeley, 1996).

A existência de um sistema especializado para o processamento da informação verbal ou fonológica é bem determinada (Baddeley, 1986). A independência entre os sistemas responsáveis pelo armazenamento da informação fonológica e visuoespacial foi estabelecida em estudos comportamentais com sujeitos normais (Logie, 1986; Logie, Zucco, \& Baddeley, 1990), em estudos neuropsicológicos (De Renzi \& Nichelli, 1975), e em estudos que utilizam técnicas de imagens funcionais do córtex (Roland \& Friberg, 1985).

Evidências de sistemas separados para o processamento da informação visual e espacial também foram obtidas em estudos psicológicos (Baddeley, 1986, 1996; Logie, 1995), 
neuropsicológicos (Darling, Della Sala, Logie, \& Cantagallo, 2006; Della Sala, Gray, Baddeley, Allamano, \& Wilson, 1999), neurológicos (Hanley, Young, \& Person, 1991; Milner \& Goodale, 1995; Nunn, Polkey, \& Morris, 1998; Ungerleider \& Mishkin, 1982) e através de imagens por ressonância magnética funcional (IRMf), que mostram o envolvimento de diferentes áreas corticais no processamento da informação espacial e visual (Courtney, Ungerleyder, Keil \& Haxby, 1997; Sala \& Courtney, 2007).

Uma das tarefas comportamentais mais utilizadas para avaliar memória espacial é o Teste de Blocos de Corsi - TBC - (Corsi, citado por Orsini, Pasquadibisceglie \& Picone, 2001). Este teste é realizado com um tabuleiro de madeira no qual estão distribuídos de forma irregular 9 blocos de dimensões iguais, que podem ser identificados pelo examinador, mas não pelo testando, através dos números em uma de suas faces. Durante a avaliação, o examinador toca com o dedo indicador uma série de blocos, numa taxa de um bloco por segundo e, logo em seguida, o sujeito deve apontar os blocos na mesma ordem em que foram apontados pelo examinador. A dificuldade é aumentada progressivamente aumentando-se o número de blocos em cada série, até que a recordação se mostre incorreta. A capacidade da memória espacial é definida pela extensão da maior série recordada corretamente (De Renzi \& Nichelli, 1975; Orsini et al., 2001). Além do número de blocos tocados em cada série o desempenho no TBC é afetado por características espaciais da série, tais como a extensão linear da trajetória, o número de cruzamentos (Busch, Farrell, Lisdahl-Medina, \& Krikorian, 2005; Orsini et al., 2001; Parmentier, Elford, \& Maybery, 2005), ou pela simetria do percurso (Rossi-Arnaud, Pieroni, \& Baddeley, 2006).

A execução do TBC envolve necessariamente um sistema de armazenamento para coordenadas espaciais, mas também é possível considerar que a série de blocos seja armazenada como um padrão inteiro de ações (Baddeley, 2007), e mesmo como um padrão de movimentos manuais. A natureza dos processos de memória envolvidos na execução do TBC ainda não é clara e tem sido objeto de vários estudos que utilizam tarefas de dissociação dupla com o objetivo de determinar os componentes do modelo de memória de trabalho envolvidos no armazenamento das séries. Por exemplo, Smyth e Scholey (1994) mostraram que o desempenho no TBC é afetado pela realização simultânea de uma tarefa secundária visuoespacial, mas não por uma tarefa secundária verbal, sugerindo o envolvimento do esboço visuoespacial no armazenamento da série. Vandierendock, Kemps, Fastame e Szmalec (2004) mostram que o desempenho no TBC não é afetado pela supressão articulatória, mas depende tanto do rascunho visuoespacial como do executivo central, exigido para manter a representação das séries longas. Della Sala et al. (1999) sugerem que a informação armazenada no TBC não é simplesmente codificada como um padrão espacial, mas que também apresenta um componente seqüencial importante.

Além do envolvimento de componentes dedicados ao processamento visuoespacial e de um componente seqüencial (ordem das séries) é plausível o envolvimento de um componente cinestésico subjacente ao TBC, pois o que é observado pelo sujeito durante a avaliação é exatamente uma série de movimentos dirigidos a posições espaciais, sendo tarefa do sujeito reproduzir esses movimentos. Evidências de um subsistema de armazenamento de sequências de movimentos foram apresentadas por Smyth, Pearson e Pendleton (1988) em um estudo em que os sujeitos realizavam três tarefas de memória de curto prazo: (i) o TBC, (ii) uma tarefa de memória verbal e (iii) uma tarefa de memória para movimentos corporais, na qual deveriam lembrar ou executar uma pequena série de padrões de movimentos feitos pelo experimentador (por exemplo, inclinar a cabeça para frente, levantar o braço esquerdo, dar um passo a frente, etc.). Smyth e Pendleton (1989) sugerem que a memória para movimentos corporais e manuais observados visualmente envolve um processo diferente daquele utilizado para memorizar posições espaciais, e que o sistema de memória de trabalho deve contar com um subsistema cinestésico específico para armazenar séries de movimentos, e um para armazenar informação espacial, cada qual com capacidade de armazenar a ordem na qual as ações devem ser realizadas.

Em resumo, a execução do TBC parece envolver tanto um sistema de memória baseado em coordenadas visuoespaciais como um sistema cinestésico, também capaz de armazenar séries de movimentos. Neste estudo procuramos explorar esses sistemas comparando o desempenho na tarefa de Blocos de Corsi realizada em sua forma clássica, na qual as séries são armazenadas com base na observação visual, com o desempenho numa situação na qual o sujeito tem sua mão conduzida pelo experimentador para os blocos da série a ser memorizada, ou seja, numa situação na qual as séries são armazenadas através da informação cinestésica aferente. Até onde é de nosso conhecimento, este tipo de tarefa de memória para movimentos passivos não foi relatado na literatura, embora sua importância já tenha sido apontada há 30 anos (Laslo \& Bairtow, 1980). Além disso, procuramos determinar se a existência desses dois sistemas poderia ser confirmada pelo fracionamento desenvolvimental. Esta técnica foi utilizada inicialmente para explorar uma possível distinção entre os componentes visual e espacial da memória de trabalho (Hitch, citado em Logie \& Pearson, 1997). A técnica está baseada na avaliação da taxa de desenvolvimento de diferentes funções cognitivas. Se o desempenho de um tipo de função cognitiva se desenvolve numa taxa que é diferente daquela observada para outro tipo de função, isso pode ser tomado como um indicativo de que as duas funções utilizam sistemas cognitivos diferentes. Logie e Pearson (1997) mostraram, por exemplo, num estudo com crianças de 5 a 12 anos, que a memória para padrões visuais é melhor do que a memória para série de movimentos para alvos espaciais, e que essa diferença tende a aumentar nas crianças mais velhas, corroborando a separação entre o sistema visual e o espacial.

\section{Método}

\section{Participantes}

Oitenta crianças na faixa etária de 7 a 10 anos, de ambos os sexos e em bom estado geral de saúde, participaram deste experimento por livre e espontânea vontade, após autorização dos pais ou responsáveis. As crianças estudavam no ensino 
fundamental (1aa a $4^{\mathrm{a}}$ série) de uma escola municipal. No grupo de sete anos participaram 18 crianças ( 9 meninas); no grupo de 8 anos participaram 20 crianças (9 meninas); no grupo de 9 anos participaram 20 crianças ( 9 meninas); no grupo de 10 anos participaram 22 crianças (14 meninas). Este projeto foi aprovado pelo Comitê de Ética em Pesquisa, Processo CEP $\mathrm{n}^{0}$ : 089, em 28/5/2003.

\section{Material}

Os participantes foram submetidos a uma bateria de testes voltados à avaliação de funções relacionadas à coordenação motora, memória visuoespacial, cinestésica e verbal numa mesma sessão e no período regular de aula. O Teste de Blocos de Corsi, utilizado para avaliar a memória visuoespacial, foi construído de acordo com a descrição de Orsini et al. (2001). Trata-se de um tabuleiro branco com 260 × $320 \mathrm{~mm}$, ao qual estão fixados de forma irregular nove blocos brancos de 40 x 40 x $40 \mathrm{~mm}$, numerados em um dos lados, de forma que possam ser identificados pelo experimentador, mas não pelo examinando.

A coordenação motora foi avaliada através de um protocolo baseado em O'Sullivan e Schmitz (1993). A avaliação da capacidade da memória verbal para dígitos foi realizada com base no protocolo da escala WISC (Wechsler, 1955). Óculos com lentes pintadas de preto foram utilizados para impedir que os participantes vissem o tabuleiro de Corsi durante a avaliação da memória cinestésica. Os testes foram aplicados individualmente em uma sala clara, arejada e silenciosa.

\section{Procedimento}

O sujeito era introduzido no ambiente de avaliação, convidado a sentar-se numa carteira escolar à frente do examinador. As atividades a serem desenvolvidas eram explicadas e dava-se início à sessão, que durava aproximadamente 45 minutos. Todas as crianças passavam, na mesma ordem, pela avaliação da coordenação motora, da memória verbal para dígitos e pelo TBC, visual e cinestésico.

Na aplicação da tarefa dos blocos de Corsi, em cada prova, o examinador tocava com o dedo indicador da mão direita o topo de cada bloco, no ritmo de um bloco por segundo. Imediatamente após a apresentação da série os participantes eram instruídos a tocar os blocos indicados (“Agora você!"). Todos os blocos tocados pelo participante, independentemente de estarem corretos ou não, foram anotados na ficha de avaliação. Foram elaboradas 14 séries de blocos variando em extensão (3, 4, 5, 6 e 7 blocos) e número de cruzamentos ( $0,1,2$ e 3 cruzamentos). Foram utilizadas cinco séries sem cruzamento (2-9-3, 7-8-6-4, 2-4-9-5-1, 2-7-9-6-1-4, 7-8-9-3-1-2-4), quatro séries com um cruzamento (7-6-4-8, 2-9-4-1-5, 2-9-7-4-1-6, 7-8-9-1-3-4-2), três séries com dois cruzamentos (2-5-9-1-4, 2-9-1-4-7-6, 4-31-9-7-8-2), e duas séries com três cruzamentos (2-9-6-7-1-4, 7-3-2-9-1-4-8), totalizando 14 séries.

Antes do início da avaliação havia um pequeno ensaio no qual o examinador apresentava duas séries de 2 blocos. A avaliação era interrompida caso o participante o desejasse, caso contrário, todas as séries eram apresentadas.

Depois de completada a avaliação da memória visuoespacial, o tabuleiro do TBC foi utilizado para avaliar a memória cinestésica, mas agora com o sujeito com os olhos vendados. As mesmas séries utilizadas na avaliação da forma visual foram utilizadas na avaliação da memória cinestésica. Nessa avaliação o experimentador conduzia a mão do sujeito aos blocos a serem memorizados. Ao início de cada série o examinador deslocava a mão do sujeito para a região central do tabuleiro, a uma altura de aproximadamente $3 \mathrm{~cm}$ acima dos blocos, e então a conduzia de bloco em bloco a uma taxa de um bloco por segundo. No momento da recordação a mão era novamente levada ao centro do tabuleiro e o sujeito era instruído a tocar os blocos da série. Como na forma clássica, a avaliação era interrompida caso o participante o desejasse; caso contrário, todas as séries eram apresentadas.

A avaliação da coordenação motora, realizada através do protocolo modificado de O'Sullivan e Schmitz (1993), envolveu os seguintes movimentos: dedo no nariz (a criança deve levar a ponta do dedo indicador até a ponta do nariz); dedo ao dedo do terapeuta (a criança deve tocar com a ponta do seu dedo indicador, o dedo indicador do avaliador; dedo ao dedo da criança (a criança deve aproximar os dedos indicadores das mãos opostas); alternância de nariz para dedo (a criança deve tocar alternadamente a ponta do nariz e a ponta do dedo do terapeuta com o dedo indicador); oposição dos dedos (a criança deve tocar a ponta do polegar com a ponta de cada dedo em sequência); abertura e fechamento do punho (a criança deve alternar entre abertura e fechamento do punho); percussão de mão (a criança deve percutir 6 vezes com as palmas das mãos, sobre os joelhos); dedo que aponta e ultrapassagem do dedo que aponta (com os braços estendidos, a criança deve apontar para os indicadores do examinador, elevar os braços retos sobre a cabeça e, em seguida, abaixá-los gradualmente, alinhando novamente os indicadores com os indicadores do examinador); desenho de um círculo imaginário no ar e, finalmente, fixação e sustentação do membro superior (o paciente sustenta por 30 segundos os braços horizontalmente, voltados para a frente, mantendo ombros à $90^{\circ}$ )

A avaliação da capacidade da memória verbal para dígitos foi baseada no protocolo da escala WISC (Wechsler, 1955). Esta avaliação tinha início com uma série de dois dígitos, utilizada para treino. Compreendida a tarefa, tinha início o teste com uma série de três dígitos. Se a série com três dígitos fosse repetida corretamente, o examinador passava a uma nova série, acrescida de um dígito, e assim sucessivamente, até que o sujeito fracassasse em dois ensaios de uma mesma série.

\section{Resultados}

O desempenho na tarefa Corsi foi estimado em função do número de posições lembradas corretamente pelos sujeitos em cada série, atribuindo-se um ponto à recordação correta de uma posição na ordem apresentada e 0,5 pontos para a recordação de uma posição correta, porém fora da ordem apresentada. A proporção entre a soma dos pontos obtidos em uma série e o total de pontos possíveis para a série foi utilizada como uma estimativa do desempenho em cada série. Os resultados foram analisados em função da combinação da modalidade (visual, cinestésica), da extensão da série (3, 4, 5, 6 e 7 blocos), e do número de cruzamentos em cada série $(0,1,2$ e 3 cruzamentos). Um resumo 
dos dados obtidos em função da modalidade, extensão e número de cruzamentos em cada série é apresentado na Tabela 1.

Dois fatores experimentais manipulados neste estudo, a extensão das séries memorizadas e o número de cruzamentos em cada série, não podem ser manipulados de forma independente, uma vez que o numero de cruzamentos é limitado pela extensão da série. Desta forma, para avaliar o efeito desses fatores relacionados à complexidade da série foram realizadas análises parciais separadas para avaliar o efeito da extensão e do número de cruzamentos (Figura 1- Extensão da Série).

Tabela 1

Porcentagem de respostas corretas na tarefa de blocos de Corsi em função da extensão das séries (N) nos quatro niveis de cruzamentos para as duas modalidades de memória.

\begin{tabular}{|c|c|c|c|c|c|c|c|c|c|c|c|c|}
\hline \multirow[b]{3}{*}{ Cruzamentos } & \multicolumn{5}{|c|}{ Visual } & \multirow[b]{3}{*}{ Média } & \multicolumn{5}{|c|}{ Cinestésica } & \multirow[b]{3}{*}{ Média } \\
\hline & \multicolumn{5}{|c|}{$N$} & & \multicolumn{5}{|c|}{$N$} & \\
\hline & 3 & 4 & 5 & 6 & 7 & & 3 & 4 & 5 & 6 & 7 & \\
\hline 0 & 97 & 83 & 84 & 61 & 52 & 76 & 65 & 28 & 48 & 32 & 19 & 38 \\
\hline 1 & & 86 & 62 & 47 & 41 & 59 & & 22 & 38 & 24 & 14 & 24 \\
\hline 2 & & & 58 & 47 & 24 & 43 & & & 33 & 26 & 11 & 24 \\
\hline 3 & & & & 47 & 25 & 36 & & & & 22 & 15 & 18 \\
\hline Média & 97 & 85 & 68 & 50 & 36 & 53 & 65 & 25 & 39 & 26 & 15 & 26 \\
\hline
\end{tabular}

Os resultados de cada sujeito foram agrupados em função da extensão das séries memorizadas, sem levar em conta o número de cruzamentos (Figura 1A, parte da Figura 1). Os resultados médios, considerando os sujeitos agrupados segundo o sexo e idade, foram submetidos a uma análise de variância com medidas repetidas no número de cruzamentos ( 3 a 7 ) e na modalidade de memória (visual e cinestésica). O desempenho melhora com a idade numa taxa média de $4 \%$ ao ano $\left(F_{(3,72)}=4,98, p<0,001\right.$, $\left.\eta^{2}=0,17\right)$, é melhor quando as séries são memorizadas em termos visuo-espaciais ( 67\%) do que em termos cinestésicos $(34 \%)\left(F_{(1,}\right.$ $\left.{ }_{72)}=647,95, p<0,001, \eta^{2}=0,90\right)$. A cada bloco acrescentado à série memorizada o desempenho sofreu um prejuízo geral de $13 \%\left(F_{(4,288)}=266,27, p<0,001, \eta^{2}=0,79\right)$. E, este prejuízo é maior para séries visuais $(16 \%)$ do que para séries cinestésicas $(10 \%)\left(F_{(4,288)}=36,12, p<0,001, \eta^{2}=0,33\right)$. Isto acontece porque o desempenho nas séries cinestésicas menos extensas (3 e 4 blocos) já é, em média, mais prejudicado (45\%) do que o desempenho nas provas visuais com essas mesmas extensões (91\%). O desempenho não varia em função do gênero $(\mathrm{F}<1)$.

A suposição de sistemas separados para armazenamento visuoespacial e cinestésico não foi confirmada nesta análise. De acordo com essa suposição deveríamos obter uma interação

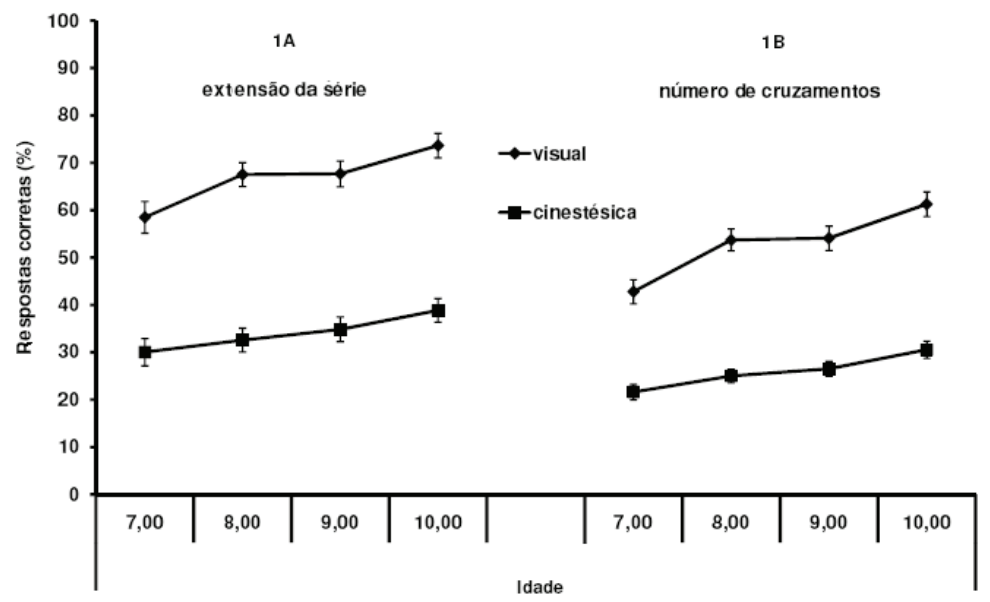

Figura 1. Porcentagem de respostas corretas para séries visuais e cinestésicas em função da idade dos participantes, da extensão (1A) e do número de cruzamentos (1B) nas séries memorizadas.

significativa entre idade e modalidade de memória, mas apesar do desempenho melhorar com a idade numa taxa maior para a informação visual (média de 4,6\%) do que para a informação cinestésica (média de 2,9\%), essa tendência não foi confirmada pela a interação entre esses fatores $\left(F_{(3,72)}=1,33, p=0,27\right)$.

Número de cruzamentos. Os dados foram reagrupados em função do número de cruzamentos (Figura 1B, parte de Figura 1) - sem levar em conta a extensão das séries memorizadas -, e submetidos ao mesmo modelo de análise de variância, com os sujeitos agrupados em função de idade e sexo, e medidas repetidas na modalidade (visual, cinestésica) e no número de cruzamentos $(0,1,2,3)$. O desempenho melhora com a idade $\left(F_{(3,72)}=7,43, p<0,00, \eta^{2}=0,24\right)$, também com uma taxa média de $4 \%$ ao ano. O desempenho também é melhor na modalidade visual $(53 \%)$ do que na cinestésica $(26 \%)\left(F_{(3,72)}=455,67, p<\right.$ $\left.0,00, \eta^{2}=0,86\right)$, e é prejudicado pelo numero de cruzamentos na série $\left(F_{(4,216)}=197,45, p<0,00, \eta^{2}=0,73\right)$, com um custo médio 
de $10 \%$ a cada cruzamento. A memória para séries visuoespaciais é mais prejudicada, com um custo médio de $13 \%$, do que as séries cinestésicas, com um custo médio de $6 \%$ a cada cruzamento $\left(F_{(3}\right.$, 216) $\left.=30,39, p<0,001, \eta^{2}=0,30\right)$.

Assim como na análise realizada em função da extensão, não se pode concluir que as taxas de variação do desempenho nas duas modalidades de memória em função da idade sejam diferentes. Embora o desempenho na tarefa visuoespacial melhore a uma taxa de aproximadamente $6 \%$, o dobro daquela encontrada para memória cinestésica, essa diferença não é consistente o suficiente para que seja considerada significativa $\left(F_{(3,72)}=2,54, p=0,06\right)$. O desempenho não varia em função do gênero $(\mathrm{F}<1)$.

Extensão da série e número de cruzamentos. Em uma análise destinada a avaliar de forma independente o papel do tamanho e do número de cruzamentos das sequências, os resultados obtidos com seqüências com seis e sete blocos foram submetidos a uma análise de variância de modelo misto com idade e sexo como fatores entre grupos, e medidas repetidas nos fatores tamanho $(6,7)$, cruzamentos $(0,1,2,3)$ e modalidade (visual, cinestésica). De maneira geral os resultados replicam as análises anteriores, todos os efeitos principais são significativos, exceto gênero. $\mathrm{O}$ efeito do número de cruzamentos é diferente nas duas modalidades $\left(F_{(3,216)}=11,31, p<0,001, \eta^{2}=0,14\right)$. Comparando-se o desempenho nas séries sem cruzamento e nas séries com um, dois ou três cruzamentos, verifica-se que nas sequências visuais a introdução do cruzamento provocou um prejuízo médio de $17 \%$, enquanto que nas séries baseadas na informação cinestésica esse prejuízo foi de aproximadamente $6 \%$. O efeito do número de cruzamentos também é diferente nas series com seis e sete blocos $\left(F_{(3,216)}=5,63, p<0,001, \eta^{2}\right.$ $=0,07)$. Nas séries com seis blocos a introdução de um ou mais cruzamentos provoca um prejuízo médio de $10 \%$, enquanto que nas séries com sete blocos, o prejuízo chega a 18\% (em média) nas séries com dois e três cruzamentos. Nas provas com dois e três cruzamentos, o prejuízo provocado pelo aumento de um bloco na série memorizada é mais acentuado nas séries visuais $(22 \%)$ do que nas séries na modalidade cinestésica $(10 \%)\left(F_{(3,}\right.$ 216) $\left.=6,06, p<0,001, \eta^{2}=0,08\right)$.

Análise da posição serial. Para avaliar o desempenho em função da posição serial do bloco na série apresentada para memorização, os resultados obtidos em cada série foram re-analisados levando-se em conta a identificação correta de cada bloco em função da posição serial ocupada na série memorizada. Estas análises foram feitas separadamente para séries de extensões diferentes considerando, alem da idade e do sexo dos participantes, os fatores modalidade de memória (visual, cinestésica) e a posição serial do item (1-7). A Tabela 2 apresenta um resumo dos parâmetros da análise de variância para os fatores modalidade, posição e para a interação entre

Tabela 2

Parâmetros das análises de variância (para as taxas de acertos nas duas modalidades de memória em função da idade, da posição e da interação entre esses fatores para as séries com diferentes extensões.

\begin{tabular}{|c|c|c|c|c|c|c|c|c|c|c|c|c|}
\hline \multirow[b]{2}{*}{ Extensão } & \multicolumn{3}{|c|}{$\begin{array}{l}\text { Idade } \\
(3,72)\end{array}$} & \multicolumn{3}{|c|}{$\begin{array}{c}\text { Modalidade } \\
(1,72)\end{array}$} & \multicolumn{3}{|c|}{ Posição } & \multicolumn{3}{|c|}{ Modalidade x Posição } \\
\hline & $F$ & $p$ & $\eta^{2}$ & $F$ & $p$ & $\eta^{2}$ & $F$ & $p$ & $\eta^{2}$ & $F$ & $p$ & $\eta^{2}$ \\
\hline 3 & 0,74 & 0,53 & & 83,5 & 0,001 & 0,54 & $\begin{array}{c}14,28 \\
(2,144)\end{array}$ & 0,001 & 0,17 & $\begin{array}{c}14,84 \\
(2,144)\end{array}$ & 0,001 & 0,17 \\
\hline 4 & 1,30 & 0,28 & & 434,9 & 0,001 & 0,86 & $\begin{array}{c}44,20 \\
(3,216)\end{array}$ & 0,001 & 0,38 & $\begin{array}{c}7,99 \\
(3,216)\end{array}$ & 0,001 & 0,10 \\
\hline 5 & 3,58 & 0,02 & 0,13 & 123,7 & 0,001 & 0,63 & $\begin{array}{c}160,30 \\
(4,288)\end{array}$ & 0,001 & 0,69 & $\begin{array}{c}12,45 \\
(4,288)\end{array}$ & 0,001 & 0,15 \\
\hline 6 & 5,69 & 0,001 & 0,19 & 124,6 & 0,001 & 0,63 & $\begin{array}{l}261,66 \\
(5,360)\end{array}$ & 0,001 & 0,78 & $\begin{array}{c}7,35 \\
(5,360)\end{array}$ & 0,001 & 0,09 \\
\hline 7 & 10,52 & 0,001 & 0,30 & 133,4 & 0,001 & 0,65 & $\begin{array}{c}87,17 \\
(6,432)\end{array}$ & 0,001 & 0,54 & $\begin{array}{c}30,99 \\
(6,432)\end{array}$ & 0,001 & 0,08 \\
\hline
\end{tabular}

Nota. Parâmetros das análises de variância $(F)$, probabilidades $(p)$ associadas, graus de liberdade (fator, erro) e eta quadrado $\left(n^{2}\right)$.

esses fatores.

Esta análise confirma as anteriores na medida em que mostra uma melhora do desempenho com a idade e uma vantagem da memória visual sobre a cinestésica. A posição serial é marcada por um forte efeito de primazia. A interação entre Modalidade de memória e posição do bloco na série (Figura 2) mostra que o efeito de primazia está presente em ambas as modalidades, mas é mais acentuado nas provas de memória cinestésica, neste caso não existe efeito de recência. $\mathrm{O}$ padrão é diferente nas provas visuais. Nestas provas o teste post-hoc de Newmann Keuls ( $p$ $=0,05)$ confirma que nas provas com três blocos o desempenho não é estatisticamente diferente nas três posições; já nas provas com quatro blocos existe um efeito de recência significativo, com a recordação do terceiro e do quarto bloco melhor do que a recordação do segundo.

Concordando com o predomínio quase que absoluto de destros $(96 \%)$ sobre os canhotos $(4 \%)$, a avaliação da coordenação motora mostrou uma vantagem nítida da mão direita, com uma pontuação relativa de $92 / 100$, sobre a esquerda, com uma pontuação relativa de $88 / 100\left(F_{(1,72)}=102,01 ; p<\right.$ $\left.0,001, \eta^{2}=0,59\right)$. A coordenação motora melhora com idade $\left(F_{(3,72)}=5,73 ; p<0,001, \eta^{2}=0,19\right) \mathrm{e}$, embora os meninos mais novos tenham uma pontuação melhor do que as meninas, essa diferença tende a desaparecer nas crianças com 9 e $10 \operatorname{anos}\left(F_{(3,}\right.$ $\left.{ }_{72)}=3,40 ; p=0,022\right)$. A avaliação do span verbal mostrou que as meninas têm uma capacidade de memória maior $(4,9)$ do que os meninos $(4,5)\left(F_{(1,72)}=4,1 ; p=0,046, \eta^{2}=0,16\right)$. O span verbal não variou de forma significativa entre as idades $(\mathrm{F}<1) \mathrm{e}$ 


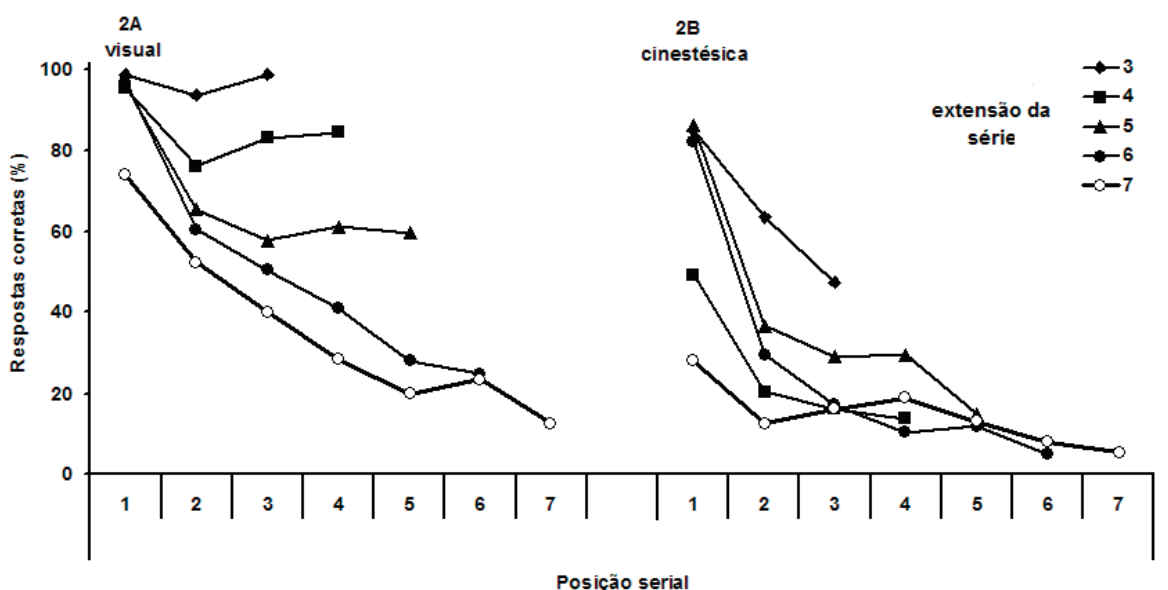

Figura 2. Porcentagem de respostas corretas em função da posição serial ocupada pelo bloco na série memorizada, para séries de todas as extensões, nas duas modalidades de memória (visual e cinestésica).

também não foi afetada pela interação entre idade e sexo $(\mathrm{F}<1)$.

Uma análise da correlação entre o desempenho nas avaliações realizadas mostra que desempenho escolar está relacionado ao span verbal $(\mathrm{r}=0,50, \mathrm{p}<0,01)$ e, de forma menos acentuada, ao desempenho na versão cinestésica do TBC ( $\mathrm{r}=$ $0,22, \mathrm{p}<0,05)$. O span verbal se relaciona de forma significativa ao desempenho nas duas modalidades do TBC (visual, $r=0,20$, cinestésica, $r=0,22$, ambas com $p<0,05)$. Curiosamente existe uma correlação significativa entre a avaliação da coordenação motora e o desempenho no TBC visual $(r=0,24, p<0,05)$, mas não com o TBC cinestésico. E, como era de se esperar, existe uma correlação relativamente alta entre o desempenho nas duas modalidades do $\operatorname{TBC}(0,53, p<0,01)$.

\section{Discussão}

Neste estudo exploramos a relação entre a memória para posições espaciais codificadas a partir da visão e a partir da informação cinestésica produzida pela movimentação passiva da mão para posições no espaço. Nossa suposição inicial era que a representação espacial baseada na informação cinestésica poderia ser diferenciada da representação espacial baseada na informação visual através de taxas de desenvolvimento diferenciadas para esses dois tipos de informação. Nossos resultados mostram que, tanto quando consideramos a extensão das séries memorizadas como o número de cruzamentos o desempenho tende a melhorar com a idade numa taxa maior para a informação visual do que para a informação motora, mas esta diferença não é estatisticamente significativa. Taxas de desenvolvimento diferentes para representações baseadas na informação visual e motora surgem apenas quando consideramos o efeito de cruzamentos nas séries com 6 e 7 blocos. E, mesmo neste caso a interação é apenas marginal e não nos permite conclusões seguras.

De maneira geral a análise das séries em termos do número de blocos memorizados e do número de cruzamentos corrobora os estudos relacionados na literatura, mostrando que a dificuldade na realização da tarefa dos blocos de Corsi aumenta com o número de blocos e, para séries com uma extensão determinada, aumenta com o número de cruzamentos (Busch et al., 2005; Orsini et al., 2001; Parmentier et al., 2005). Esse padrão acontece da mesma forma para as duas modalidades de memória, sugerindo que um mesmo processo de armazenamento e/ou de recitação está envolvido nas duas modalidades.

De acordo com Parmentier et al. (2005) e Parmentier \& Andrés (2006) o efeito da extensão e do numero de cruzamentos sobre a recordação pode ser o resultado de dois processos, a codificação e a recitação do material memorizado. Nossos resultados parecem excluir a codificação como uma das origens do efeito do cruzamento, ou pelo menos restringem o uso que podemos dar ao termo. O número de cruzamentos tem o efeito muito similar sobre as memórias codificadas com base na informação visual ou motora, o que nos sugere que a origem do efeito do cruzamento deveria estar localizada no processo de recitação.

A memória para a localização espacial de estímulos visuais (letras, padrões abstratos, cores, etc) é marcada por grande efeito de recência e ausência do efeito de primazia (Galera \& Fuhs, 2003; Walker, Hitch \& Duroe, 1993). Nossos resultados mostram, na situação visual, um efeito de primazia marcado por um pequeno efeito de recência para as séries visuais mais curtas (com extensão 3 e 4). Por sua vez, a recordação das séries motoras é marcada por um efeito de primazia acentuado para todas as extensões. Se considerarmos que durante a execução clássica do TBC a informação é codificada inicialmente em termos visuoespaciais e depois recodificada em termos motores, para a realização da resposta, poderemos supor que as diferenças entre as curvas de posição serial entre as duas modalidades de memória são produzidas pela existência de um componente visual em uma das representações. Esta suposição está de acordo com a literatura que mostra uma correlação entre o desempenho no TBC e em tarefas visuais de curto prazo (por exemplo, Della Sala et al., 1999) e com estudos sobre o processamento de ordem serial que utilizam estímulos visuais (Smith, Hay, Hitch, \& Horton, 2005).

Embora nossos resultados não permitam afirmar de maneira conclusiva a existência de um sistema motor independente de um sistema espacial, eles nos levam a acreditar que o desempenho 
no TBC clássico é resultado da contribuição de componentes motores e visuoespaciais. Próximos estudos poderão esclarecer o peso específico do componente motor, assim como sobre a origem do efeito dos cruzamentos sobre o desempenho no TBC. Além disso, nosso estudo abre a possibilidade de se avaliar a memória espacial a curto prazo em deficientes visuais, campo que, até onde é do nosso conhecimento, ainda não foi explorado.

\section{Referências}

Baddeley, A. D. (1986). Working memory. Oxford: Clarendon Press.

Baddeley, A. D. (1996). Exploring the central executive. Quarterly Journal of Experimental Psychology, 49A, 5-28.

Baddeley, A. D. (2000). The episodic buffer: a new component of working memory? Trends in Cognitive Sciences, 4, 417-423.

Baddeley, A. D. (2007). Working memory, thought, and action. United Kingdom: Oxford University Press.

Busch, R.M., Farrell, K., Lisdahl-Medina, K., \& Krikorian, R. (2005). Corsi block-tapping task performance as a function of path configuration. Journal of Clinical and Experimental Neuropsychology, 27, 127-134.

Courtney, S. M., Ungerlayder, L. G., Keil, K., \& Haxby, J. V. (1997). Transient and sustained activity in a distributed neural system for human working memory. Nature, 386, 608-611.

Darling, S., Della Sala, S., Logie, R. H., \& Cantagallo, A. (2006). Neuropsychological evidence for separating components of visuo-spatial working memory. Journal of Neurology, 253, 176-180.

Della Sala, S., Gray, C., Baddeley, A., Allamano, N., \& Wilson, L. (1999). Pattern span: a tool for unwelding visuo-spatial memory. Neuropsychologia, 37, 1189-1199.

De Renzi, E., \& Nichelli, P. (1975). Verbal and non-verbal short-term memory impairment following hemispheric damage. Cortex, 11, 341-354.

Galera, C., \& Fuhs, C. C. L. (2003). Memória visuo-espacial a curto prazo: os efeitos da supressão articulatória e de uma tarefa aritmética. Psicologia: Reflexão e Crítica, 16, 337-348.

Hanley, J., Young, A., \& Person, N. (1991). Impairment of the visuo-spatial sketchpad. Quarterly Journal of Experimental Psychology, 43A, 101-125.

Laslo, J. I., \& Bairstow, P. J. (1980). The measurement of kinaesthetic sensitivity in children and adults. Developmental Medicine and Child Neurology, 22, 454-464.

Logie, R. H., \& Pearson, D. G. (1997). The inner eye and the inner scribe of visuo-spatial working memory: evidence from developmental fractionation. European Journal of Cognitive Psychology, 9, 241-257.

Logie, R. H. (1986). Visuo-spatial processing in working memory. Quarterly
Journal of Experimental Psychology, 38A, 229-247.

Logie, R. H. (1995). Visuo-spatial working memory. Hillsdale: Erlbaum.

Logie, R. H., Zucco, G. M., \& Baddeley, A. (1990). Interference with visual short-term memory. Acta Psychologica, 75, 55-74.

Milner, D. A., \& Goodale, M. A. (1995). The visual brain in action. United Kingdom: Oxford University Press.

Nunn, J., Polkey, C., \& Morris, R. (1998). Selective spatial memory impairment after right unilateral temporal lobectomy. Neuropsychology, 25, 726-737.

Orsini, A., Pasquadibisceglie, M., \& Picone, L. (2001). Factors which influence the difficulty of the spatial path in Corsi Block-Tapping Test. Perceptual Motor Skills, 200, 732-738.

O'Sullivan, S. B., \& Schmitz, T. J. (1993). Fisioterapia: avaliação e tratamento ( $2^{\mathrm{a}}$ edição). São Paulo: Manole.

Parmentier, F. B. R., \& Andrés, P. (2006). The impact of path crossing on visuospatial serial memory: Encoding or rehearsal effect? Quarterly Journal of Experimental Psychology, 59, 1867-1874.

Parmentier, F. B. R., Elford, G., \& Maybery, M. T. (2005). Transitional information in spatial serial memory: path characteristics affect recall performance. Journal of Experimental Psychology: Learning, Memory, \& Cognition, $31,412-427$

Roland, P. E., \& Friberg, L. (1985). Localization of cortical areas activated by thinking. Journal of Neurophysiology, 53, 1219-1243.

Rossi-Arnaud, C., Pieroni, L. \& Baddeley, A. (2006). Symmetry and binding in visuo-spatial working memory. Neuroscience, 139, 393-400.

Sala, J. B., \& Courtney, S. M. (2007). Binding of what and where during working memory maintenance. Cortex, 43, 5-21.

Smyth, M., Pearson, N. A., \& Pendleton, L. R. (1988). Movement and Working Memory: Patterns and Positions in Space. Quarterly Journal of Experimental Psychology, 40A, 497-514.

Smyth, M. M., \& Pendleton, L. R. (1989). Working memory for movements. Quarterly Journal of Experimental Psychology, 41A, 235-250.

Smyth, M. M., \& Scholey, K. A. (1994). Interference in spatial immediate memory. Memory \& Cognition, 22, 1-13.

Ungerleider, L. G., \& Mishikin, M. (1982).Two cortical visual systems. In D. J. Ingle, M. A. Goodale \& R. J. W. Mansfield (Orgs.), Analysis of Visual Behavior (pp. 549-586). Boston: Mit Press.

Vandierendock, A., Kemps, E., Fastame, M. C., \& Szmalec, A. (2004). Working memory components of the Corsi blocks task. British Journal of Psychology, 95, 57-79

Walker, P., Hitch, G. J., \& Duroe, S. (1993). The effect of visual similarity on short-term memory for spatial location: implications for the capacity of visual short-term memory. Acta Psychologica, 83, 203-224.

Wechsler, D. (1955). Teste de inteligência para adultos (Wais) Manual. (H. F. Alvarez, Trad.). Buenos Aires: Paidós.

Cesar Galera, Livre Docente pela Faculdade de Filosofia, Ciências e Letras de Ribeirão Preto, USP (FFCLRPUSP), é professor associado na mesma Universidade. Endereço para correspondência: Departamento de Psicologia e Educação - FFCLRP - USP. Av. Bandeirantes 3900, Ribeirão Preto - SP, CEP.: 14040-901. Telefones: (16)3602-3760/(16)3633-5015 (Fax). E-mail: algalera@usp.br

Adriana Lis Pereira de Souza, mestre em Psicobiologia pela Faculdade de Filosofia, Ciências e Letras de Ribeirão Preto, USP (FFCLRP-USP), é professora do Centro Universitário Barão de Mauá, Ribeirão Preto. 